\title{
Application of ERT Survey for Addressing the Issues of Urban Rain Storm Water Logging in the Qassim Province of Saudi Arabia
}

\author{
Faisal K. Zaidi, Osama M. K. Kassem, Mohammad T. Hussein, \\ Abdulaziz M. Al-Bassam \\ SGSRC, Department of Geology and Geophysics, College of Science, King Saud University, Riyadh, KSA \\ Email: okassem@KSU.EDU.SA
}

Received February 10, 2012; revised March 11, 2012; accepted April 15, 2012

\begin{abstract}
The Qassim province is one of the most arid regions of Saudi Arabia, however heavy rainfall events have led to water logging problems in the populated centers like Buraidah mainly as a consequence of construction in low lying areas and valleys. Urban rain storm water logging problem were reported at 4 localities in the Buraidah Municipal area after heavy rainfall in November 2008 and March 2009. The logged water from these sites were directed to 4 manmade lakes however the stagnant water in these lakes posed a serious environmental threat mainly in the form of water borne disease. Keeping this problem in mind, a detailed geophysical investigation in the form of Electrical Resistivity Tomography was carried out using the SYSCAL Pro Unit at these 4 locations with a dipole-dipole configuration. The survey was helpful in delineating the wet zones from the dry ones and based on the interpretations the optimum depth and sites of 4 injections bore-wells were determined at each locality. These injection bore-well would serve the dual propose of getting rid of the stagnant water in these lakes and also recharging the underlying aquifers.
\end{abstract}

Keywords: Qassim; Arid Regions; Water Logging; ERT Survey; Aquifer Recharge

\section{Introduction}

Central Saudi Arabia experiences an arid type of climate with mean annual rainfall rarely exceeding $150 \mathrm{~mm}$. The low rainfall has resulted in scanty vegetation in the region except for the wadis where farms and date palm plantations can be seen due to the availability of groundwater. However the chance of flash floods increases to a great extent due to lack of vegetation cover in the events of heavy rainfall.

The city of Buraidah which is the administrative capital of the Qassim province has undergone rapid urbanization in the recent years and due to lack of proper urban planning a lot of low lying areas and wadi beds have been allotted to housing colonies. During the heavy rainfall in the month of November 2008 and March 2009, many such housing colonies in the low lying areas were inundated by flood water.

The municipal corporation of Qassim decided to divert this water to man-made lakes in Buaraidah City. The stagnant water in the lakes in turn became a threat for the environment by providing the breeding ground for mosquitoes and other water borne disease. Thus it was decided to drill a few bore wells in these manmade lakes with the dual purpose of recharging the aquifer and getting rid of the stagnant surface water thereby preventing environmental degradation.

Keeping this objective in mind Electrical Resistivity Survey was carried out at 4 locations (Figure 1) in Buraidah for investigating the depth of the wet zone in these localities for estimating the approximate depths of injection bore wells to be drilled to get rid of the logged water collected during heavy rainfall events.

\section{Methodology}

Electrical Resistivity methods have been widely used for surveys where the sub-surface resistivity is heterogeneous and can provide valuable information regarding bed rock geometry [1]. Electrical Resistivity is a function of the water content in the subsurface strata, the porosity of the geologic material, the electrical conductivity of water, the rock type an temperature, [2-4].

The electrical potential difference created by an electrical current passing through a material is measured which helps in calculating the resistance of the material. The variations in resistivity with depths helps in the construction of a 2D profile and is considered to be the most 


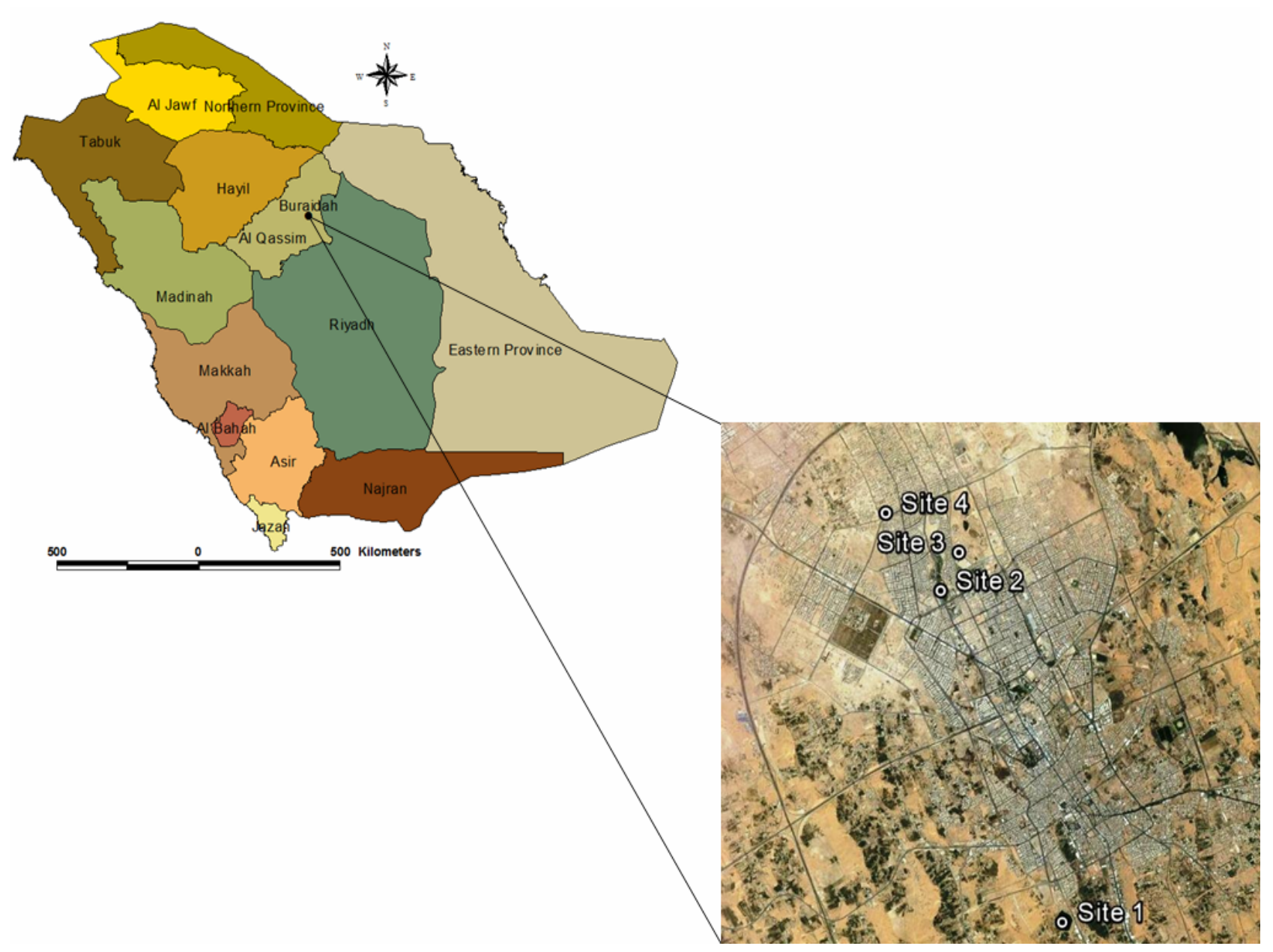

Figure 1. Location map of the study area.

non-destructive techniques for studying the subsurface geological variations [5-7].

The surveys at all the 4 locations were carried out using the Dipole-Dipole configuration with the unit electrode spacing ranging from 2.5 meters to 5 meters depending upon the ground clearance using the SYSCALPro 72 unit. Dipole-Dipole configuration was selected for the survey as it is more sensitive to lateral variations in electrical resistivity.

RES2DINV Software [8] was used for inverting the apparent resistivity values to a resistivity model section. The least square fitting technique [9] was used for getting the best fit for the resistivity model by iterations.

\section{Results and Discussions}

\subsection{Site 1}

The first site M1 was in the Buhairatil Khaleej (Figure 2) which is situated in the South of Burayda City. The total line length of the survey was 360 meters with the unit electrode spacing of 5 meters using dipole-dipole con- figuration. The depth of investigation at this site was around 72 meters.

\subsubsection{Result}

Figure 3 shows the result of the resistivity survey. The resistivity values range from $7.07 \mathrm{ohm} \cdot \mathrm{m}$ to $36.9 \mathrm{ohm} \cdot \mathrm{m}$.

\subsubsection{Conclusion}

The depth of investigation in the present case is about 72 meters. The resistivity value for the total depth of investigation does not show a very high contrast and in general is very low ranging from $7 \mathrm{ohm} \cdot \mathrm{m}$ to $37 \mathrm{ohm} \cdot \mathrm{m}$. indicating the presence of a wet zone throughout the entire depth of investigation. However at a depth of about 30 meters from the surface the resistivity value increases indicating the presence of relatively dry zone. This boundary (Figure 4) can well be the contact zone between alluvium and weathered limestone as the site is situated in the course of a wadi. The 2 zones of relatively high resistivity shown in Figure 6 may be due to the presence of less weathered limestones. 


\subsection{Site 2}

The second site M2 was in the Bohairatil Iskan Qadeema (Figure 5) which is situated in the Buraidah City Center. The length of the profile for this survey was 288 meters with the unit electrode spacing of 4 meters using Dipoledipole configuration. The depth of investigation at this site was around 57 meters.

\subsubsection{Result}

Since there was some water in the lake the survey was carried out on the embankments of the lake. Figure 6 shows the result of the resistivity survey carried out at Buhairatil Iskan Qadeema. The resistivity values range from $2.93 \mathrm{ohm} \cdot \mathrm{m}$ to $7000.56 \mathrm{ohm} \cdot \mathrm{m}$.

\subsubsection{Conclusion}

The results (Figure 7) clearly indicate the presence of an approximately 40 meters thick wet zone starting from 6 meters below ground level upto 46 meters below ground level. The resistivity values within this zone range from $2.93 \mathrm{ohm} \cdot \mathrm{m}$ to about $30 \mathrm{ohm} \cdot \mathrm{m}$. The lake still had some water and this probably explains the presence of a thick wet zone. Bore wells drilled to a depth greater than 45 meters could be helpful in injecting the water collected in this lake during rains.

\subsection{Site 3}

The third site M3 was in the Bohairatil Iskan Jadeeda (Figure 8) which is situated about $1 \mathrm{~km}$ North East of the site M2. The length of the profile for this survey was 288 meters with the unit electrode spacing of 4 meters using dipole-dipole configuration. The depth of investigation at this site was around 57 meters.

\subsubsection{Result}

The cross sections of the lake walls showed the presence

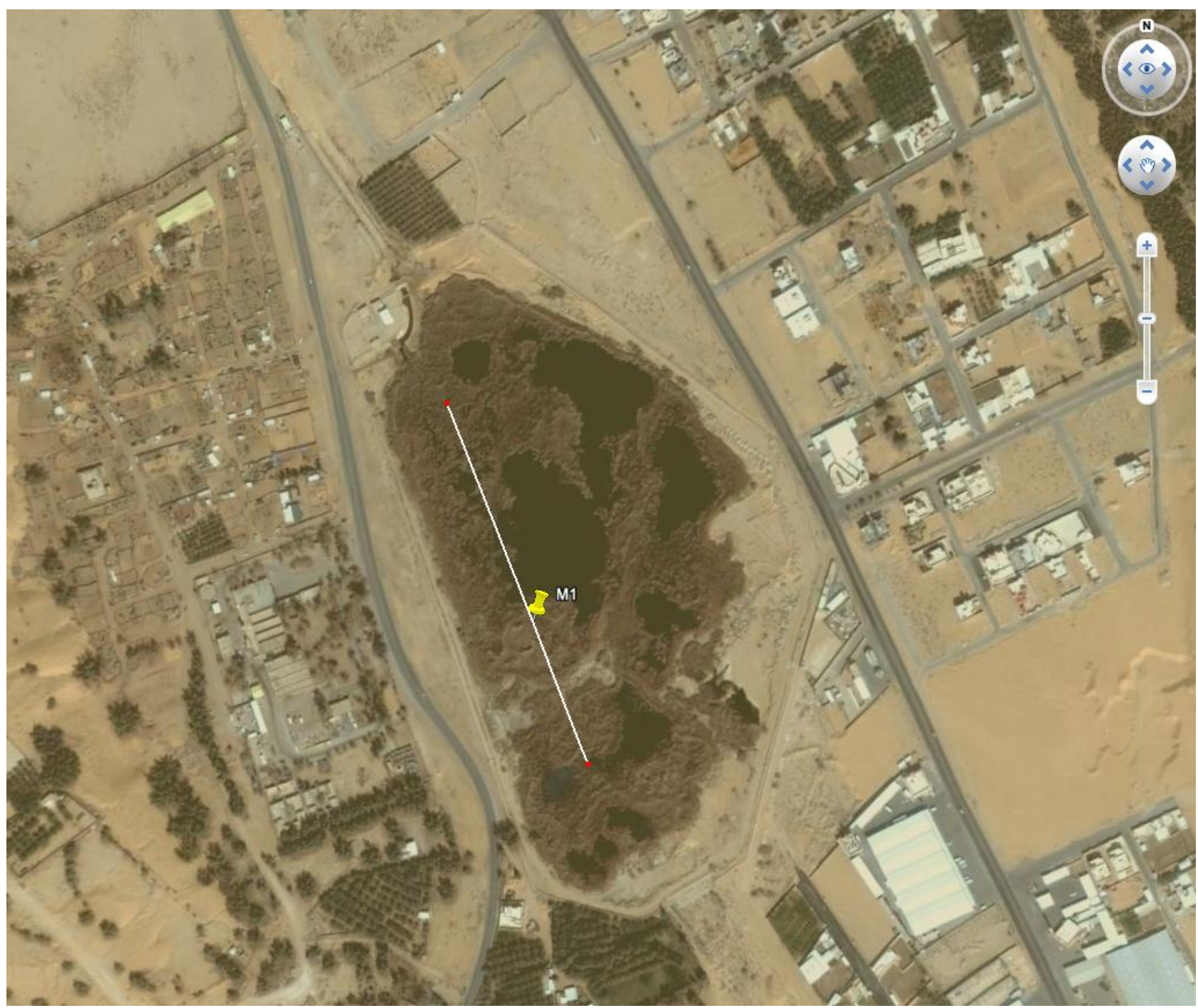

Figure 2. Location map of Buhairatil Khaleej with the direction of the survey line. 

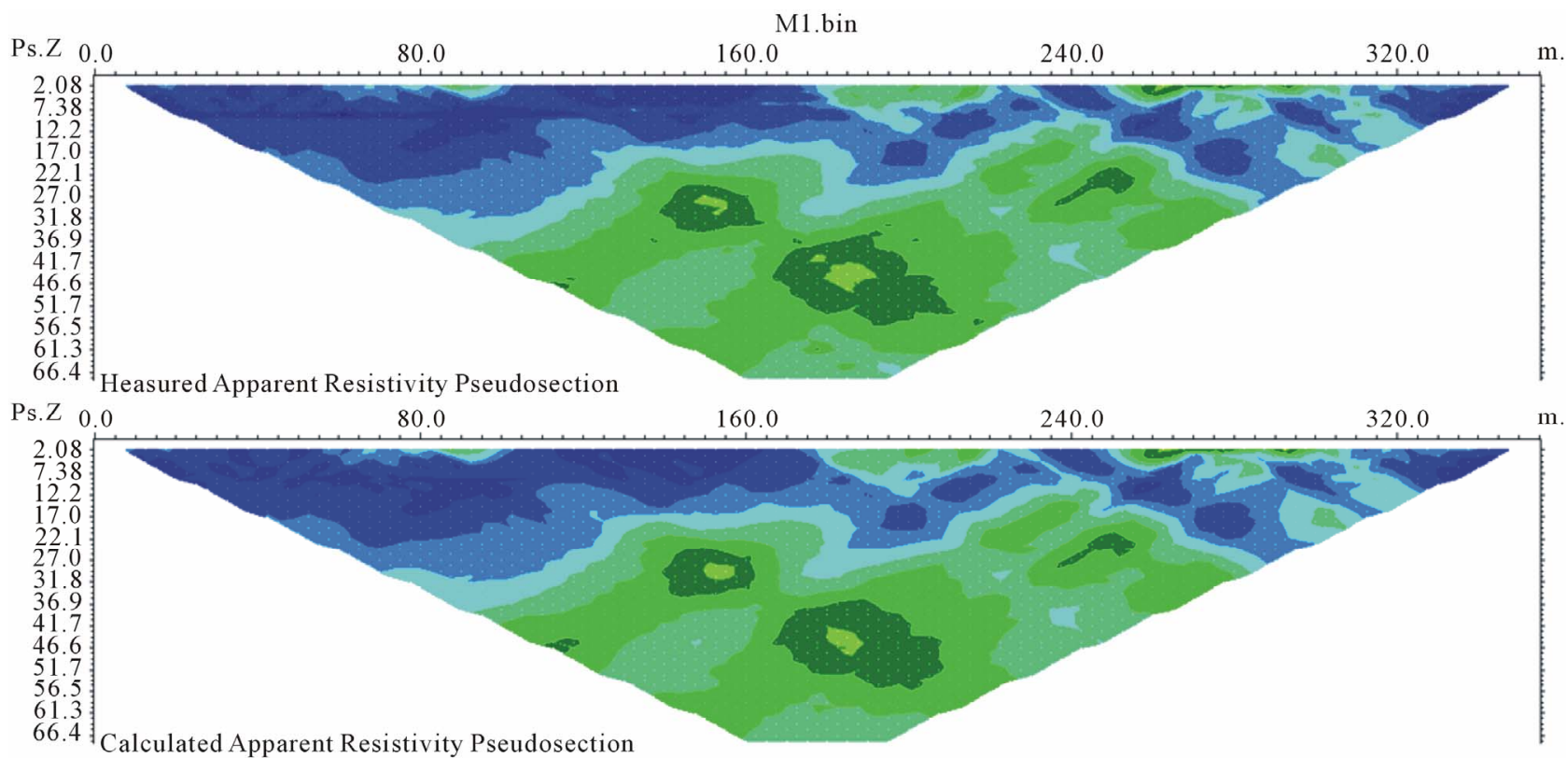

Depth Iteration 4 RMS error $=2.3 \%$

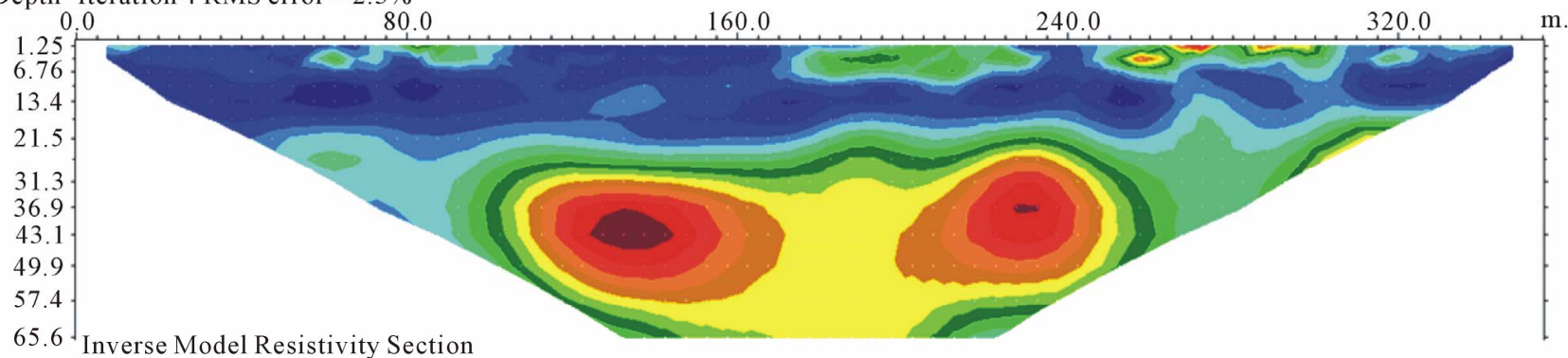

65.6 Inverse Model Resistivity Section

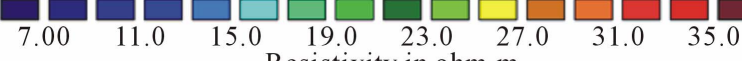

Resistivity in $\mathrm{ohm} \cdot \mathrm{m}$
Figure 3. Results of the resistivity survey at site M1.

Probable contact between the alluvium and limestone

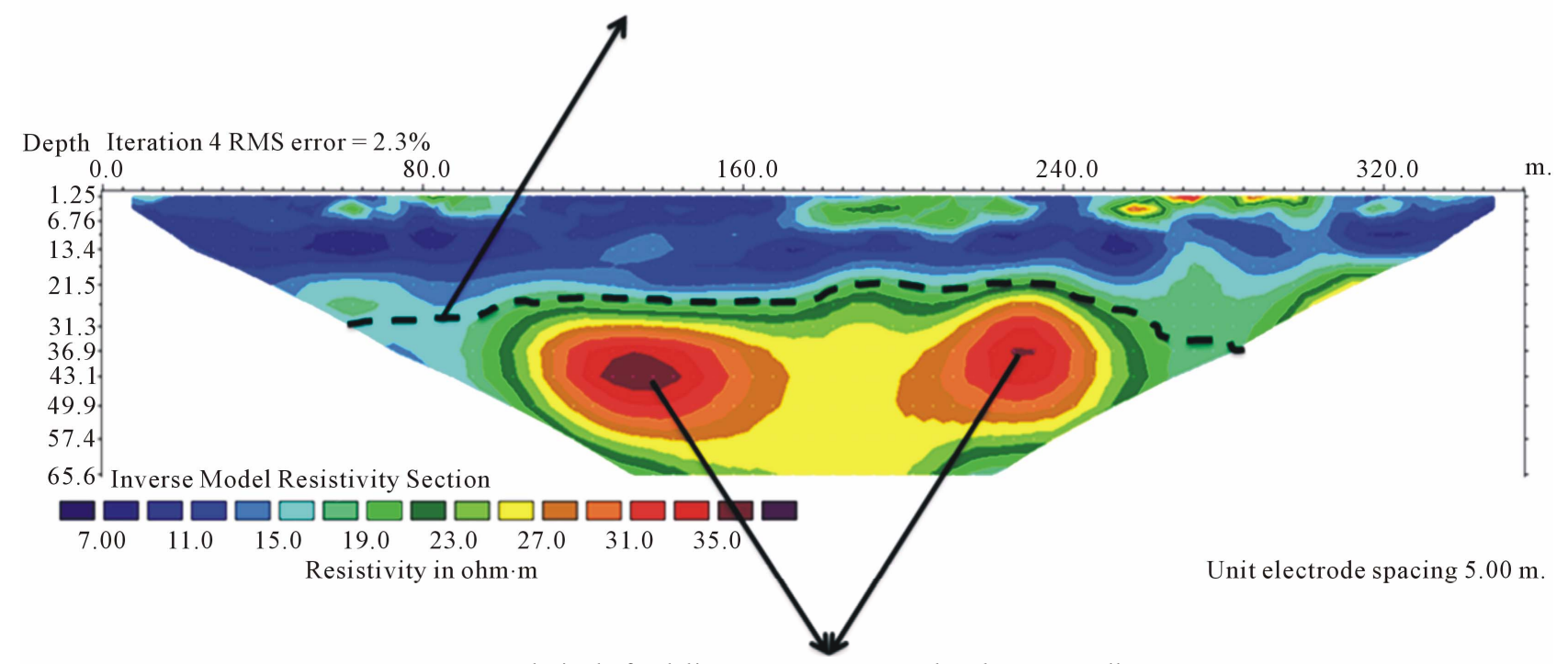

Relatively fresh limestone as compared to the surroundings

Figure 4. Interpretation of the resistivity results as site M1. 
of weathered Limestones with calcrete infillings and the presence of folds. Figure 9 shows the result of the resistivity survey carried out at Buhairatil Iskan Jadida. The resistivity values range from $0.17 \mathrm{ohm} \cdot \mathrm{m}$ to 2258.20 ohm $\cdot \mathrm{m}$.

\subsubsection{Conclusion}

The wet zone thickness in the present locality is about 35 meters with some local variations as seen in the middle of the section where the wet zone extends upto the entire depth of investigation. This fact could be explained by the presence of structural features which might have resulted in partial weathering of the limestones thus resulting in varying degree of water saturation. This difference in water saturation around this zone is clearly reflected in the resistivity contrasts in the cross-section. In the Eastern part of the profile some fresh limestone outcrops were present and it has been reflected in the form of high resistivity in the right side of the profile, (Figure 10). In general the wet zone thickness in the section varies from about 6 meters below ground level to about 40 meters below ground level. Injections well drilled to a depth of around 45 meters could solve the purpose of getting rid of excess water at this site.

\subsection{Site 4}

The fourth site M4 was in the Bohairatil Riyan (Figure 11) which is situated in the North Western part of Buraidah City. The total line length of the survey was 180 meters with the unit electrode spacing of 2.5 meters using dipole-dipole configuration. The depth of investigation at this site was around 36 meters.

\subsubsection{Result}

The cross sections of the lake walls showed the presence

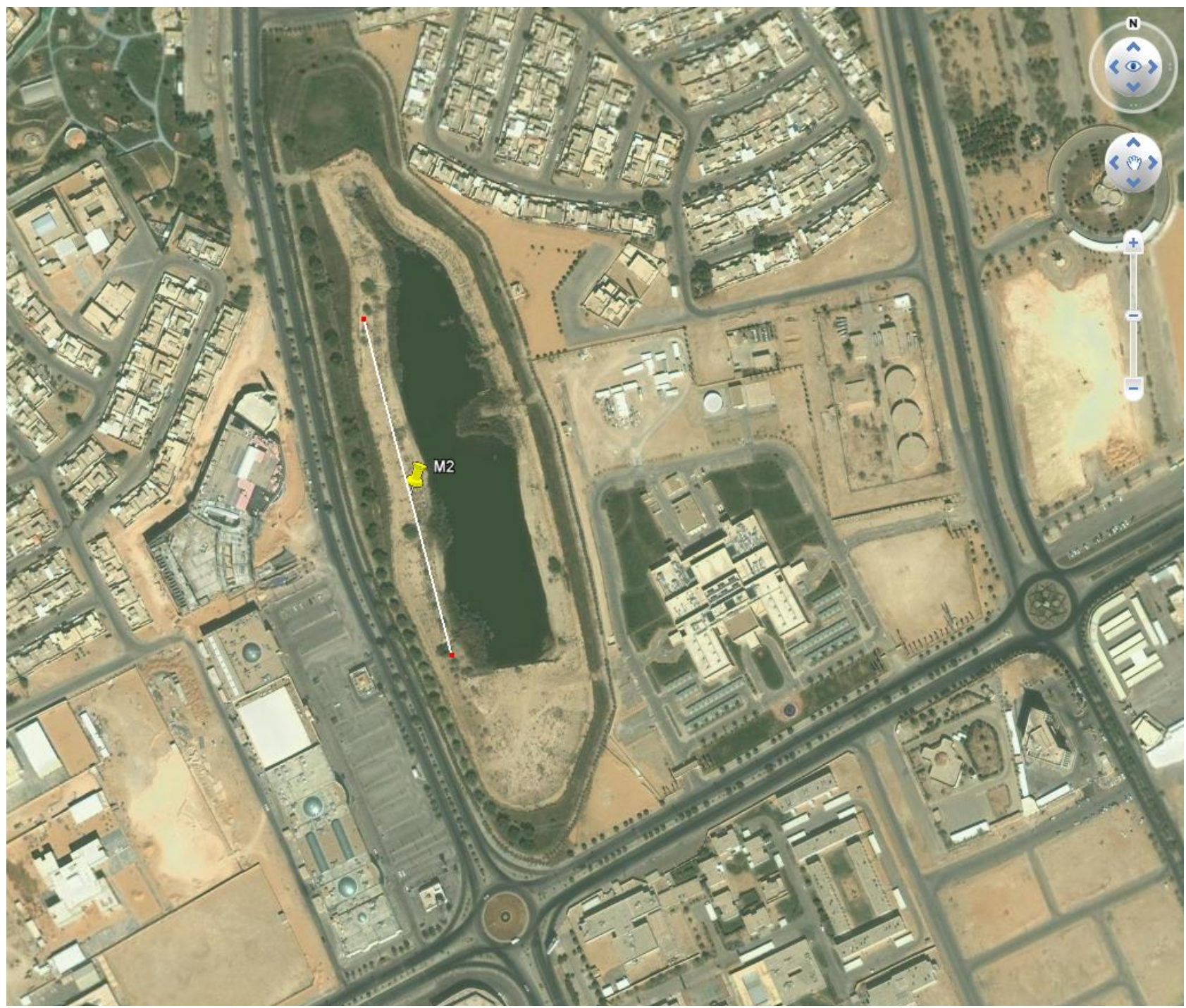

Figure 5. Location map of Bohairatil Iskan Qadeema with the direction of the survey line. 


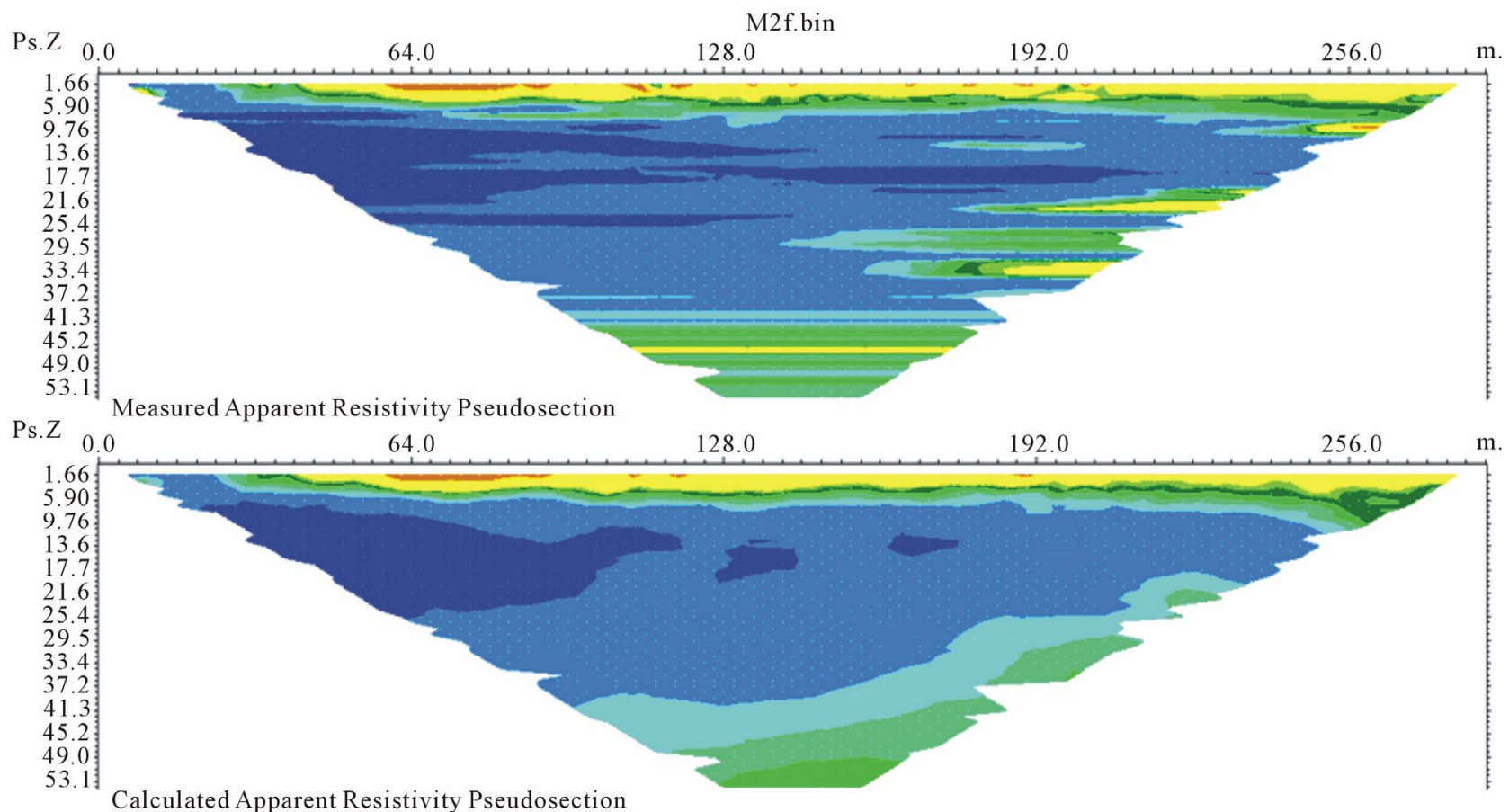

Deoth Iteration 4 RMS error $=20.8 \%$
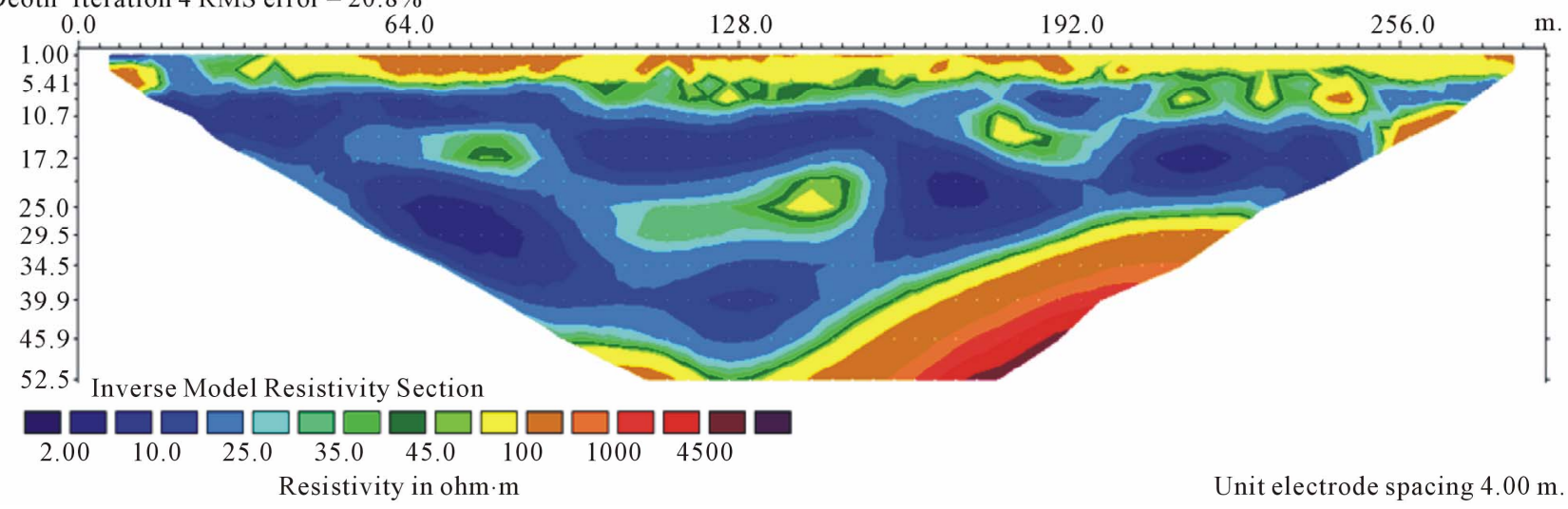

Figure 6. Results of the resistivity survey at site M2.

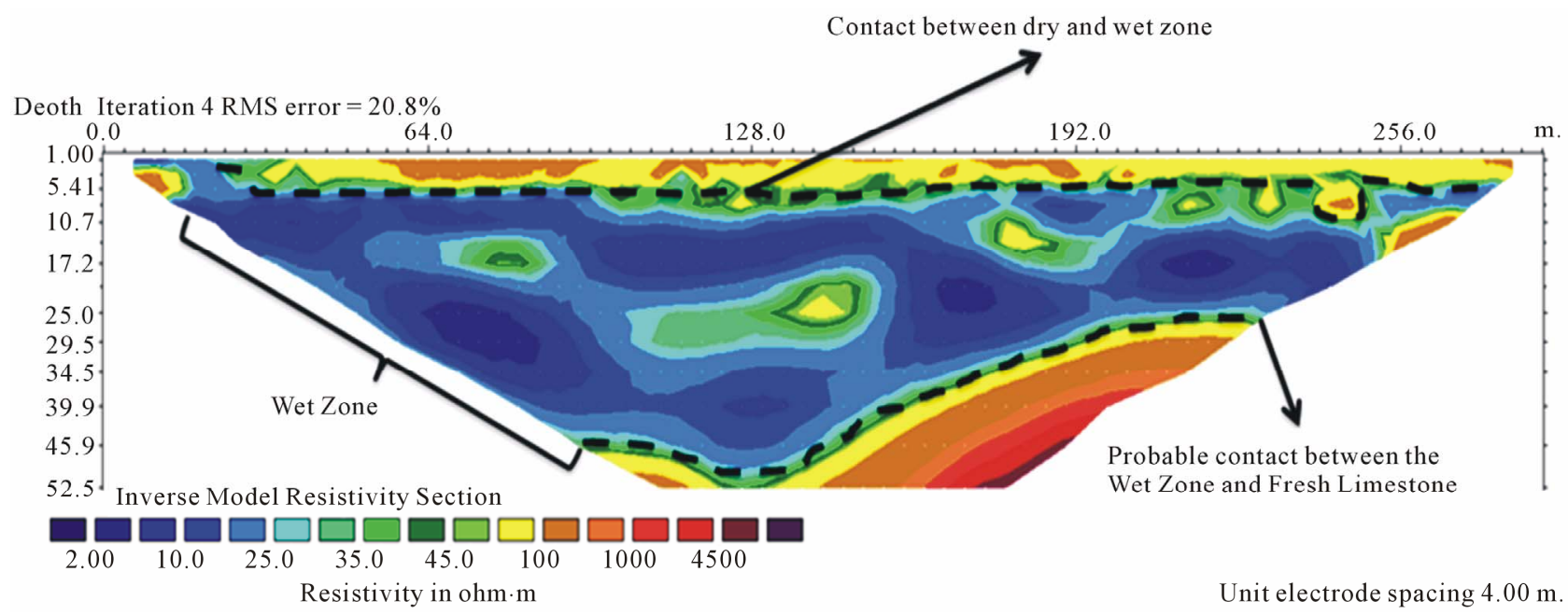

Figure 7. Interpretation of the resistivity results as site M2. 
of weathered Limestones with calcrete infillings and the presence nodal structures. Figure 12 shows the result of the resistivity survey carried out at Buhairatil Riyan Jadida. The resistivity values range from $0.81 \mathrm{ohm} \cdot \mathrm{m}$ to $137.60 \mathrm{ohm} \cdot \mathrm{m}$.

\subsubsection{Conclusion}

As mentioned earlier the resistivity values for this site ranges from $0.81 \mathrm{ohm} \mathrm{m}$ to $36.9 \mathrm{ohm} \cdot \mathrm{m}$. which indicates that neither the resistivity values nor the resistivity contrast is very high for this site. In general the section shows the presence of wet zone through the entire depth of investigation. However the depth of investigation in the present case is limited only to 36 meters due to the unavailability of open space for laying the resistivity cables. On the lower left portion of cross section in Figure 13 the probable contact between the dry and wet zone is shown at about a depth of 25 meters. From the general depth of the dry zone in the previous 3 sections it can be concluded that drilling injections wells to the depth of about 45 meters may solve the purpose of getting rid of the excess water at this site as well.

\section{Discussion}

The probable presence of alluvium was detected only at the first site M1 at Bohairatil Khaleej with a sharp contrast in resistivity value at around 30 meters from the surface and is in accordance with the field observation which

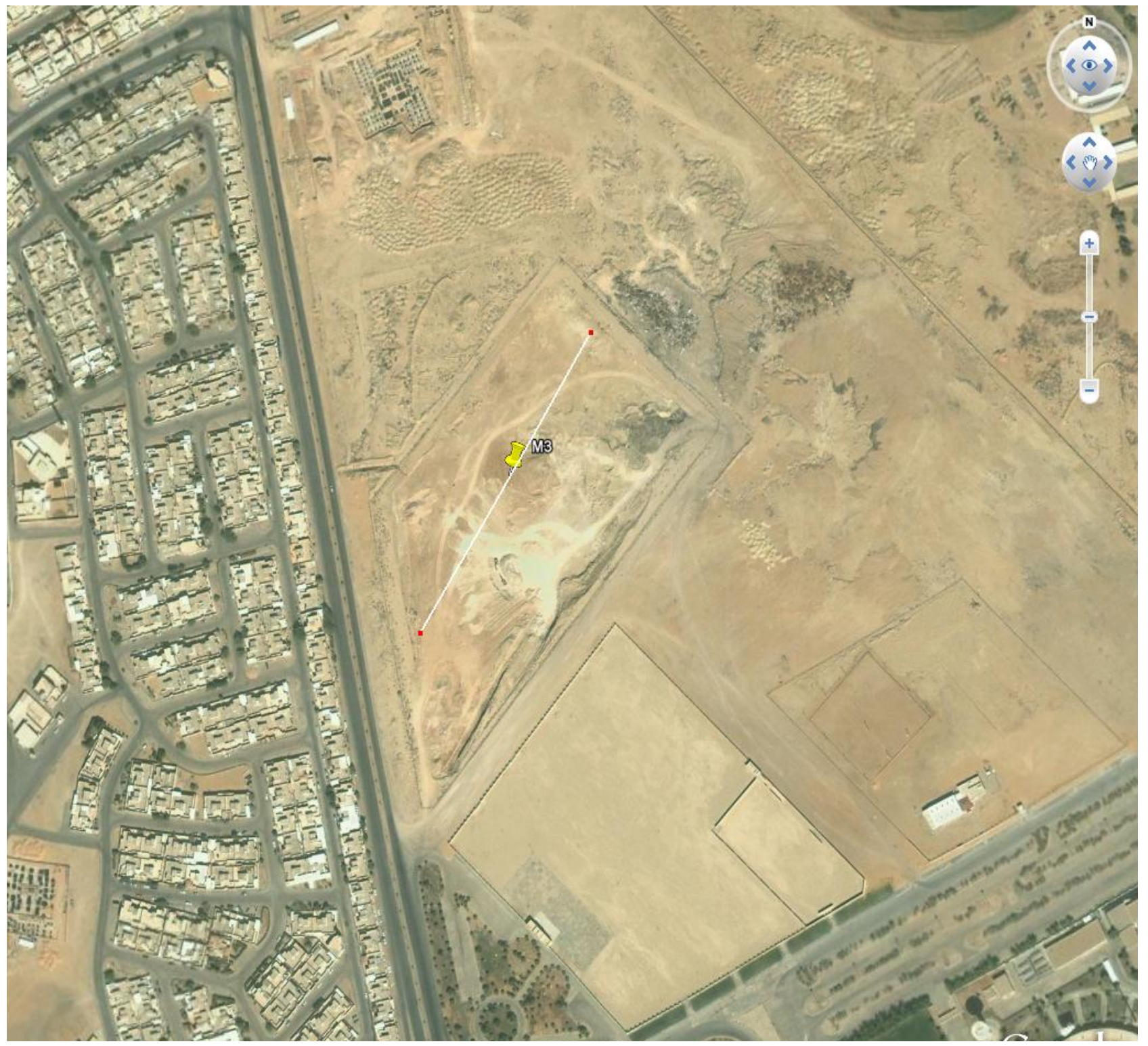

Figure 8. Location map of Bohairatil Iskan Jadeeda with the direction of the survey line. 


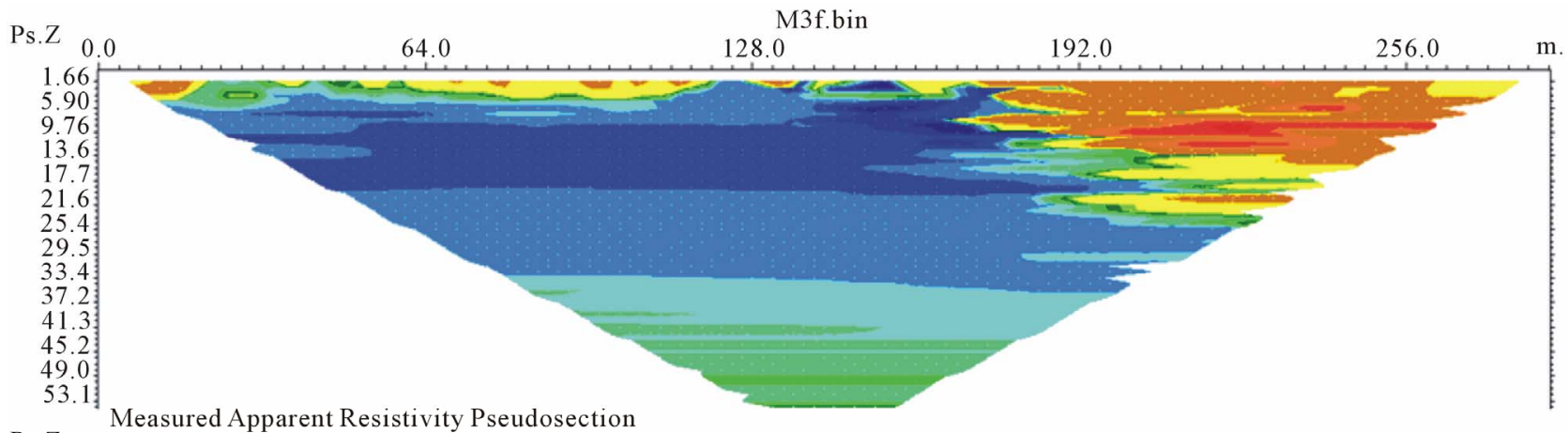
Ps.Z 0.0

Measured Apparent Resistivity Pseudosection

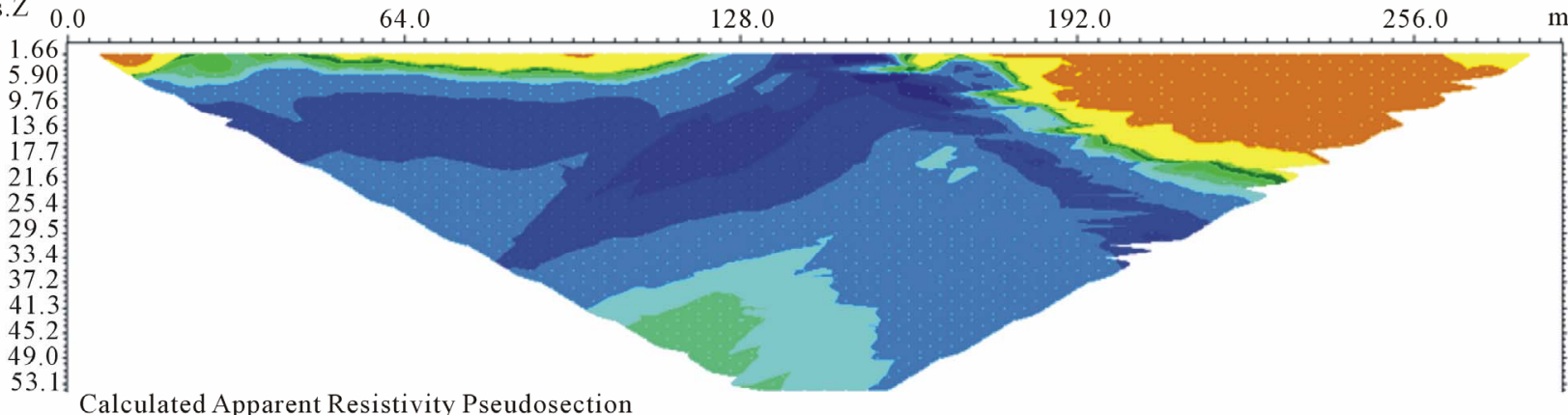

Calculated Apparent Resistivity Pseudosection

Depth Iteration 4 RMS error $=43.4 \%$

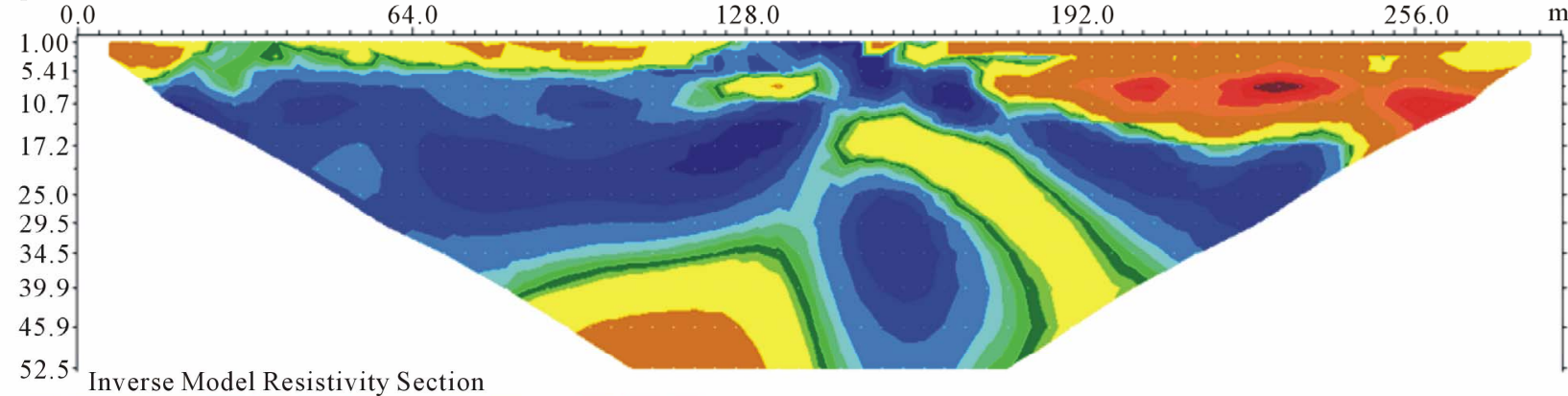

$\begin{array}{ccccccc}\square & \square .150 \quad 10.0 \quad 25.0 \quad \begin{array}{l}35.0 \quad 45.0 \quad 100 \\ \text { Resistivity in ohm } \mathrm{m}\end{array}\end{array}$

Unit electrode spacing $4.00 \mathrm{~m}$.

Figure 9. Results of the resistivity survey at site M3.

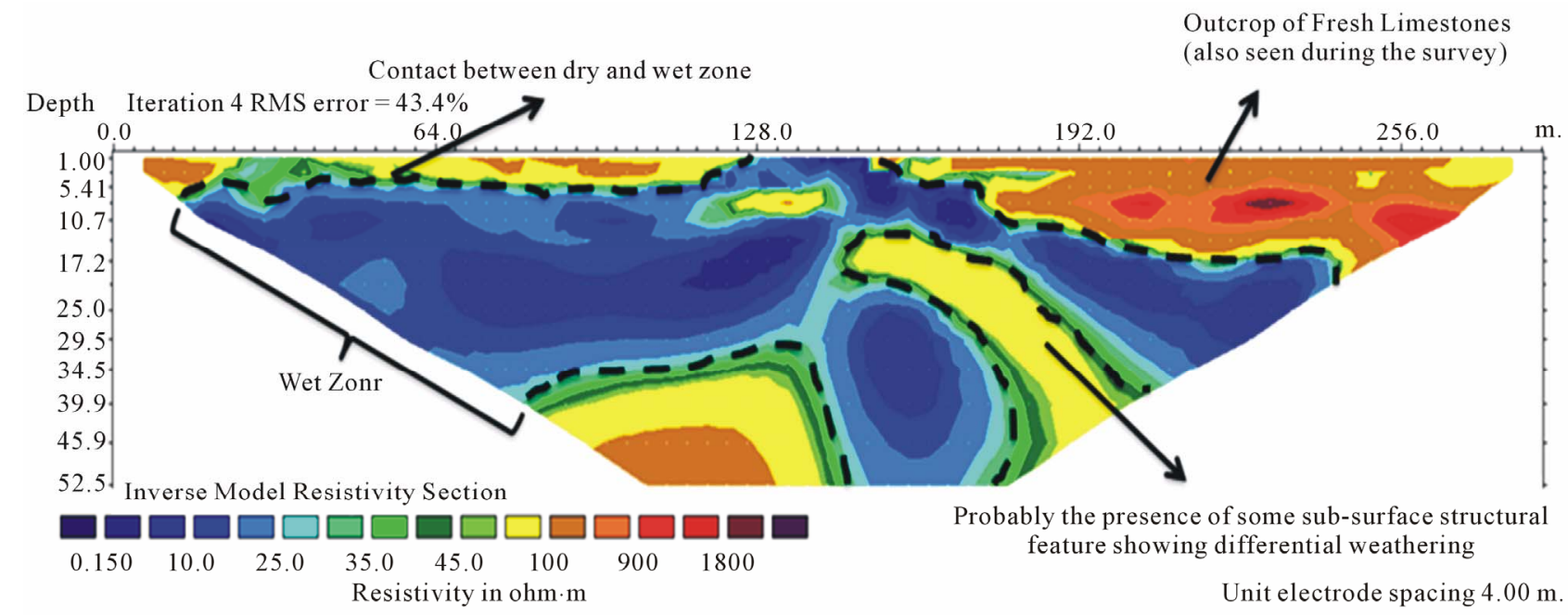

Figure 10. Interpretation of the resistivity results as site M3. 
shows that this site is located in the course of a Wadi. The resistivity values are low at the other 3 localities as well indicating the presence of wet and weathered limestones. Presence of alluvium in these localities can be ruled out based on the exposed wall sections in the lakes which show beds of limestones intercalated with calcrete infillings. At the locations M2, M3 and M4 a contrast in resistivity values are observed at a depth ranging from 30 meters to 45 meters below ground level. Wells drilled upto depths ranging from 45 meters to 55 meters in all the 4 localities can be efficient in getting rid of the excess rain water collected in these lakes during rainfall. Environmental degradation from urban rain storm water logging is becoming is becoming a serious issue mainly as a result of unplanned construction activities without taking into consideration the natural flow paths of rain water. Buraidah city in the Qassim province of Saudi Arabia faced a similar problem where the low lying housing colonies got flooded with rain water. The geophysical investigation in the form of resistivity survey proved helpful in determining the depth of dry zones in the subsurface where the logged water could be injected to serve the dual purpose of getting rid of the excess water and recharging the aquifer at the same time.

\section{Acknowledgements}

The authors would like to thank the municipality of $\mathrm{Bu}-$ raidah, Qassim province for allowing them to carry out the survey and the SGS Research Chair on Natural Hazards, King Saud University for providing the necessary

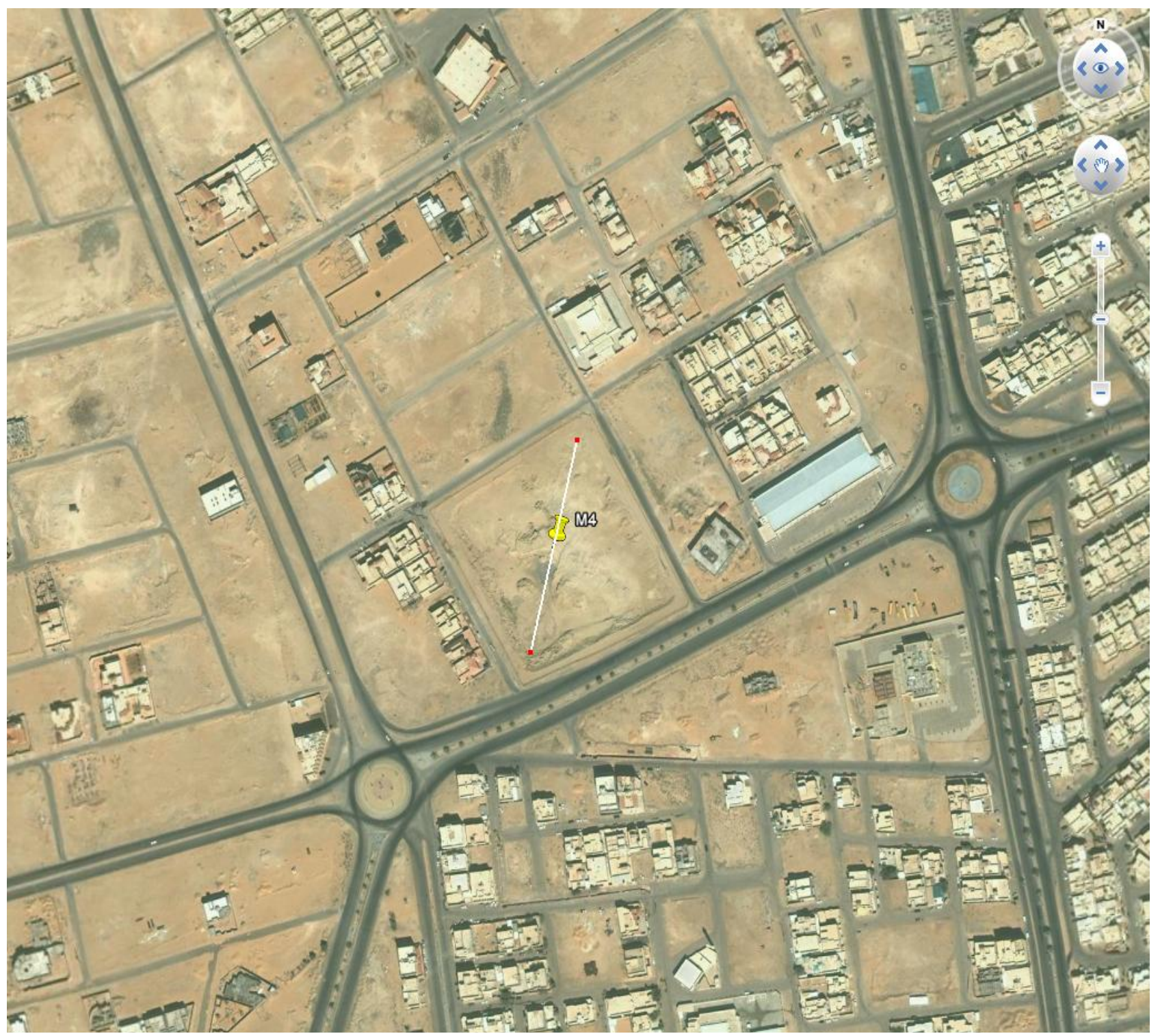

Figure 11. Location map of Bohairatil Riyan with the direction of the survey line. 

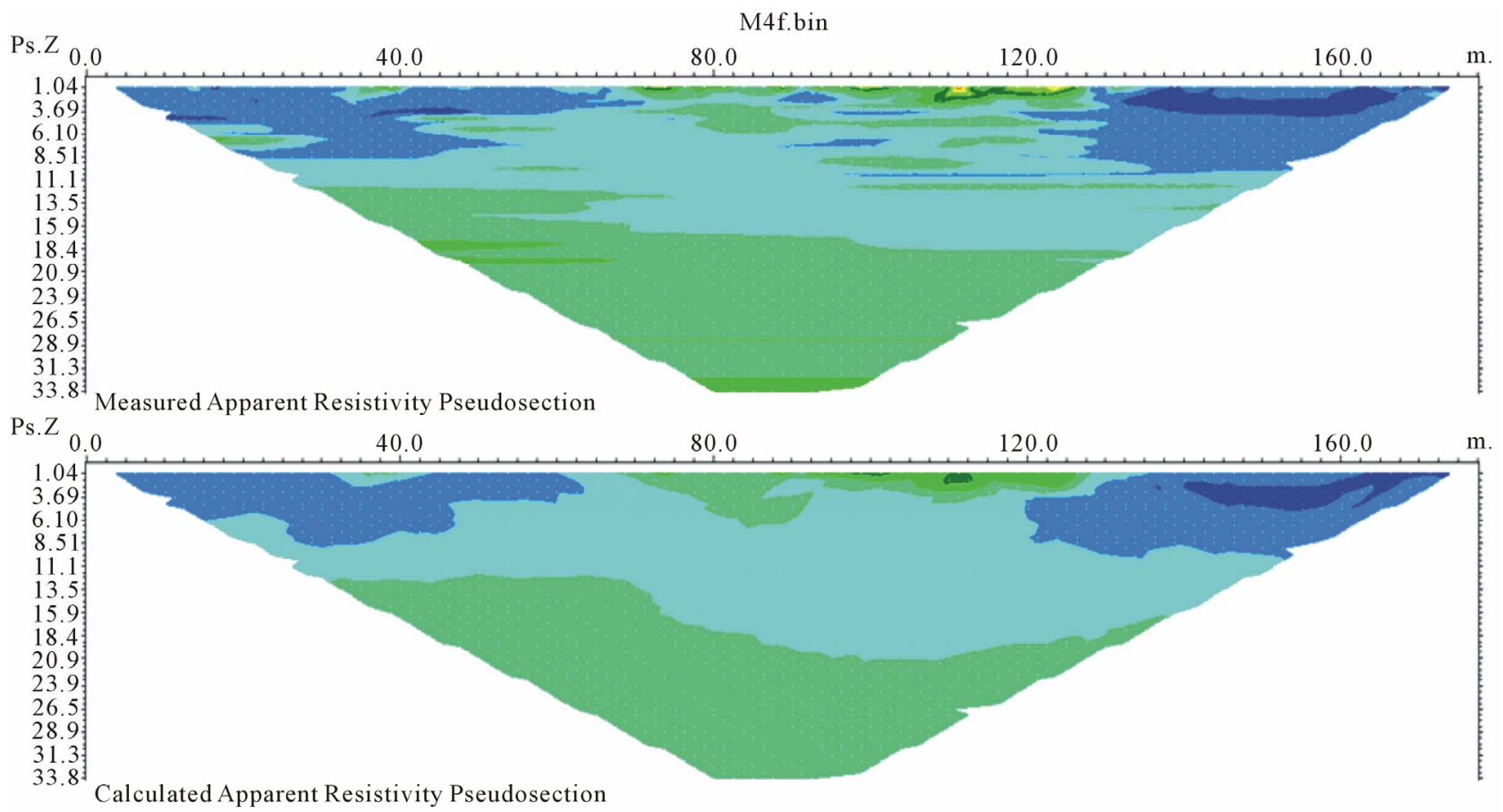

Depth Iteration 3 RMS error $=18.7 \%$

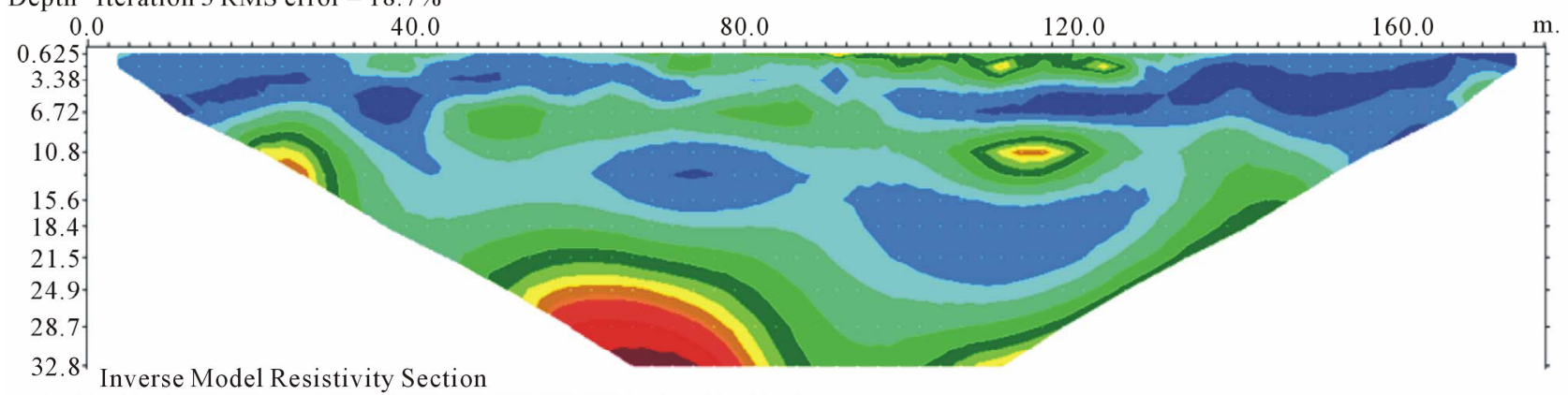

32.8 Inverse Model Resistivity Section

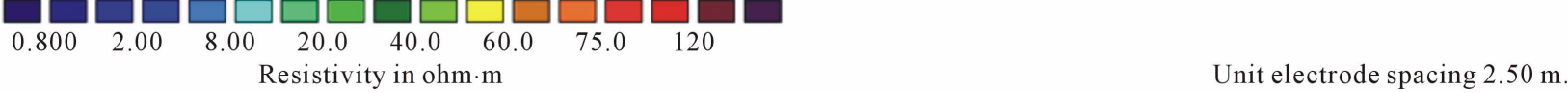

Figure 12. Results of the resistivity survey at site M4.

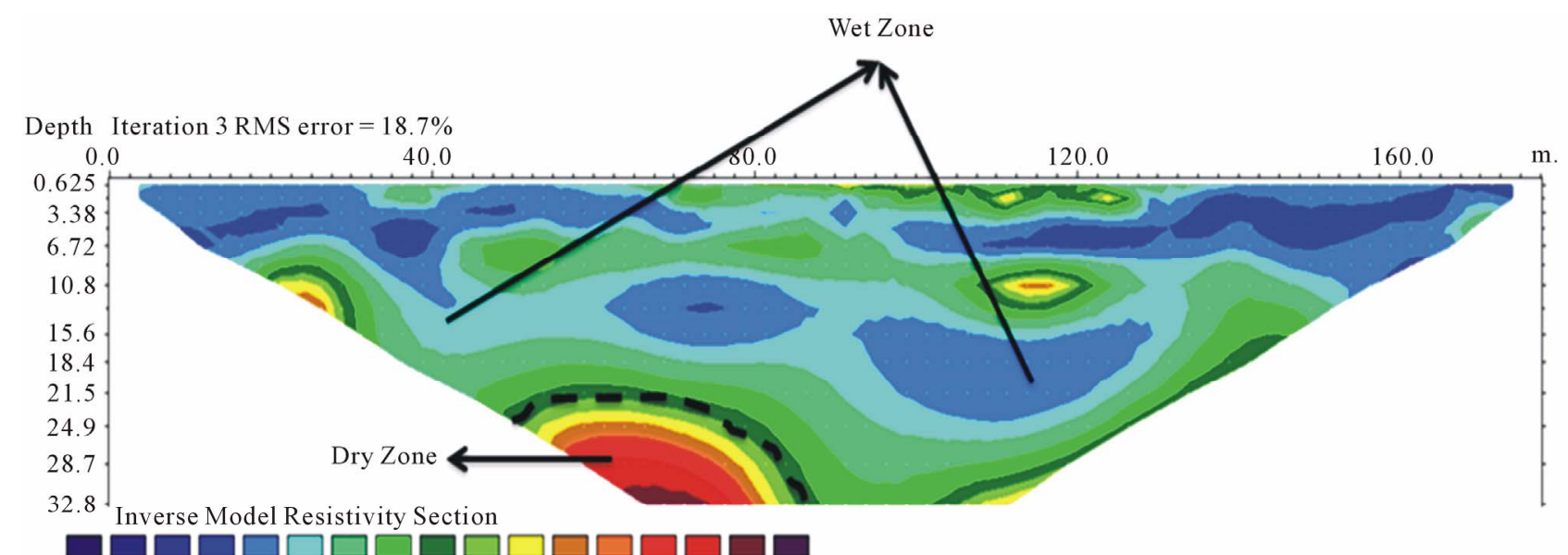

Figure 13. Interpretation of the resistivity results as site M4. 
research facilities for taking up this study.

\section{REFERENCES}

[1] M. Descloitres, L. Ruiz, M. Sekhar, A. Legchenko, J. J. Braun, M. S. Mohan and S. Subramanian, "Characterization of Seasonal Local Recharge Using Electrical Resistivity Tomography and Magnetic Resonance Sounding," Hydrological Process, Vol. 22, No. 3, 2008, pp. 384-394. doi:10.1002/hyp.6608

[2] W. M. Telford, L. P. Geldart and R. E. Sheriff, “Applied Geophysics,” 2nd Edition, Cambridge University Press, New York, 1990. doi:10.1017/CBO9781139167932

[3] A. Rein, R. Hoffman and P. Dietrich, "Influence of Natural Time Dependent Variations of Electrical Conductivity on DC Resistivity Measurements," Journal of Hydrology, Vol. 285, 2004, pp. 215-232. doi:10.1016/j.jhydrol.2003.08.015

[4] Z. Faisal and M. K. K. Osama, "Use of Electrical Resistivity Tomography in Delineating Zones of Groundwater Potential in Arid Regions: A Case Study from Diriyah Region of Saudi Arabia," Arabian Journal of Geosciences, Vol. 5, No. 2, 2012, pp. 327-333.

[5] Y. Sasaki, "Resolution of Resistivity Tomography In- ferred from Numerical Simulation,” Geophysical Prospecting, Vol. 40, No. 4, 1992, pp. 453-464. doi:10.1111/j.1365-2478.1992.tb00536.x

[6] H. Store, W. Storz and F. Jacobs, "Electrical Resistivity Tomography to Investigate Geological Structures of Earth's Upper Crust,” Geophysical Prospecting, Vol. 48, No. 3, 2000, pp. 455-471.

[7] V. Naudet, M. Lazzari, A. Perrone, A. Loperte, S. Piscitelli and V. Lapenna, "Integrated Geophysical and Geomorphological Approach to Investigate the Snowmelt-Triggered Landslide of Bosco Piccolo Village (Basilicata, Southern Italy),” Engineering Geology, Vol. 98, No. 3-4, 2008, pp. 156-157. doi:10.1016/j.enggeo.2008.02.008

[8] M. H. Loke, "RES2DINV, Ver. 3.50, Rapid 2-D Resistivity and IP Inversion Using the Least Square Method,” Geotomo Software, Penang, 2002. http://www.geoelectrical.com/contact.html

[9] M. H. Loke and R. D. Barker, "Rapid Least-Squares Inversion of Apparent Resistivity Pseudo-Sections by a Quasi Newton Method," Geophysical Prospecting, Vol. 44, No. 1, 1996, pp. 131-152. doi:10.1111/j.1365-2478.1996.tb00142.x 